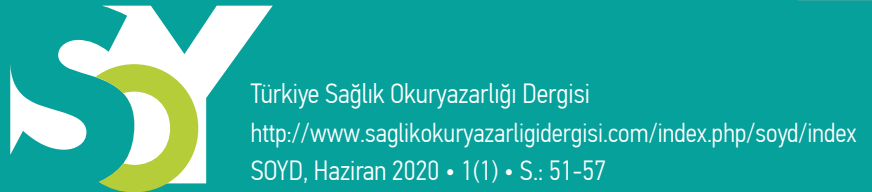

SOYD, Haziran $2020 \cdot 1(1) \cdot$ S.: 51-57
E-ISSN: 2717-7831

Başvuru | 24 Nisan 2019

Kabul | 27 Eylül 2019

DOI: $10.54247 /$ SOYD. 2020.6

\title{
Sağlıklı Aktif Başarılı Yaşlanma
}

\author{
Healthy Active Successful Aging
}

Tuğba Özdemirkan'

Zeynep Belma Şenlik ${ }^{2}$

A. Çiğdem Şimşek ${ }^{3}$

Öz

Dünyada insanlar daha uzun yaşamakta, doğum sıklığı azalmakta ve yaşlı nüfus artmaktadır. Ülkemizde, yaşlı nüfusun toplam nüfus içindeki payı 2017 yılında \%8,5'e yükseldi. Nüfus projeksiyonlarına göre, 2023 'de $\% 10,2,2075$ 'de yüzde 27,7 olacağı öngörülmektedir. Ülkemizde yaşlı bağımlılık hızı 2017 yılında \%12,6 iken 2023'de \%15,2, 2040'da \%25,3 olacağı öngörülmektedir. Nüfusun hızla yaşlanması, bazı kronik hastalıkların görülme riskini artırmakta, bunun sonucu olarak da ulusal ve uluslararası halk sağlığı için yeni ve ciddi sorunlar ortaya çıkmaktadır. Ülkemizde 65 yaş ve üzeri grubun \%90'ında 1, \%35'inde 2, \%23'ünde 3, \%15'inde 4 ve daha fazla kronik sağlık sorunu olduğu tahmin edilmektedir. "Aktif Yaşlanma" programı içinde öncelenen konular yaşamın ileri dönemlerinde de beklenmeyen ve erken ölümlerin önlenmesi, kronik hastalıkları olan bireylerin hastalıklarına bağlı engellilik durumu yaşamamaları, bireylerin ileri yaşlarında da yaşamdan zevk alabilmeleri, yaşı bireylerin toplumun sosyal, politik, ekonomik aktivitelerine katılabilmeleri, sağlık harcamalarının daha az maliyetli olması ve bu giderler için devletin sorumluluğunun sağlanmasıdır. Birey, toplum ve sağlık sistemleri tarafından yaşam boyu sağığın geliştirilmesi ve aktif yaşlanmanın öncelenmesi ile sağlıklı ve aktif yaş alabilen toplumlar oluşacaktır. Bu doğrultuda yol alan toplumlar dünya ülkeleri arasında da rekabet konusunda avantajlı olacaktır.

Anahtar Kelimeler: Sağıkı Yaşlanma, Aktif Yaşlanma, Yaşlı Sağlığı, Sağlık Okuyazarlığı, Başarıı Yaşlanma.

\footnotetext{
${ }^{1}$ Uzm. Dr., Ankara II Sağlık Müdürlüğü Halk Sağlığı Hizmetleri Başkanlığı, Ankara, tkarsag@yahoo.com

2 Uzm. Dr., Ankara İl Sağlık Müdürlüğü Halk Sağlığı Hizmetleri Başkanlı̆ı, Ankara, zeynepsenlik@gmail.com

${ }^{3}$ Dr., Ankara II Sağlık Müdürlüğü Halk Sağlığı Hizmetleri Başsanlığı, Ankara, cigdemsimsek2000@yahoo.com
} 


\begin{abstract}
People in Turkey are living longer and the rate of "NewBirth have fallen and are currently on the decline.We are becoming a population of "OLD PEOPLE"Both Globally and Nationally we are seeing that the ageingg population is on the INCREASE.It might sound "funny"but there will be more old people then young people in the world.According to recent studies on 'Ageing and Population',figures have shown that in the Year 2017 alone that in Turkey the Ageing population had risen by $8.5 \%$. Pre-Census population anticipate that current Ageing trends show a $10.2 \%$ increase for the year 2023 and a $27.7 \%$ for the year 2075 nationally. The data indicates that the 'Ageing'population rates are further on the increase and for some years those figures will even increase very 'sharply'. The evidence shows that whislt there was a 12.6\% increase for the year 2017 alone,a $15.2 \%$ increase for the year 2023 and a 'staggering' 25.3\% for the year 2040 in our Ageing Population is well estimated according to current ageing trends nationally.With the increase in our Ageing Population on the increase and well estimated for the years ahead,there poses many health challenges for our Health Care System both Nationally and Globally.Our rapid increasing Ageing population will bring with them many Chronic Health Issues and problems.At the National level we will see a large number of Serious Health Problems arise in the Age groups of people in the (65+)and over.We can see with the current Global picture that Medical Issues in the Ageing puts 'strain' on Health Systems and their ability to cope.At the National level, after analyzing all the figures it is well documented that we must have strategies in place in order to successfully provide and promote a stable and functional Health System for our Ageing Population. We at a National Level must strategically address those issues now in order to be better prepared for the years to come. With all the numbers and figures highlighting the increase in Chronic Health Problems "more the ones associated with the ageing process"then what can we do as 'Health Care Givers, Health Managers and Health promoters do?There are 5(Five) areas that we need to address for 'Healthy Ageing' and 'Healthy Active Ageing'. The areas that need to be addressed for our "Ageing Population are their "PSYCHOLOGICAL,SOCIAL,PHYSICAL,RELIGOUS AND ECONOMIC" requirements. We then 'procatively' address the needs of our Ageing Population "HOLISTICALLY".It is "fundamentally' significant that these areas are acted upon.It is of vital importance that at the National Level we have 'Strategic Plans,promotions and activities in place in order to better serve our Ageing Community and sustain a well adapted Health System for the coming years ahead.
\end{abstract}

Keywords: Healthy Living,Pro-Active Ageing,Health In The Elderly.

İnsanoğlunda ölümsüzlük, yaşlanmamak düşüncesi tarihler boyunca hep var olmuştur (Cankurtaran, 2005). Oysaki yirmi birinci yüzyılda ön plana çıkan en önemli demografik olgulardan birisi yaşlanmadır (T.C. Sağlık Bakanlığı, 2015).

Türk Dil Kurumu (TDK, 2017) sözlüğünde, yaş; bir canlının, bir olay ya da olgunun ortaya çıkışından itibaren geçen ve yıl birimi ile ölçülen zaman göstergesi olarak ifade edilmektedir. Yaşlanma; genetik bir programla düzenlenen ve organizmayı çevresel faktörlerinde etkisiyle meydana gelen yapısal ve işlevsel değişmelerle doğumdan ölüme kadar olan olaylar toplamıdır. Yaşlanma; önüne geçilmesi mümkün olmayan, kronolojik (doğum tarihine göre), biyolojik (anatomik ve fizyolojik değişikliklerle), ekonomik, sosyal (yaşlının hayattaki rolü), psikolojik yönleri ve sorunları da olan, her bireyin yaşayacağı bir süreçtir (Cankurtaran, 2005). Dünya Sağlık Örgütü (DSÖ, 2003), bu değişikliklerle seyreden yaşlıı̆ı, çevresel faktörlere uyum sağlayabilme yeteneğinin azalması olarak 
ifade etmekte, 65 yaş ve üzeri grubu yaşlılık dönemi olarak kabul etmekte ve 45-59 yaş arası orta yaş, 60-74 yaş arası yaşlılık, 75-89 yaş arası ileri yaşııık, 90 ve üstü ise ihtiyarlık olarak sınıflandırmaktadır. Birleşmiş Milletler (UN) ise standart bir ölçüt koymasa da 60 yaş üstünü yaşlı olarak değerlendirmektedir (Çolak \& Özer, 2015; UN, 2013).

Dünyada insanlar daha uzun yaşamakta, doğum sıklığı azalmakta ve yaşı nüfus artmaktadır (DSÖ, 2003). Dünyada yaşı nüfusun artış hızı $(\% 2,1)$, genel nüfus artış hızından $(\% 1,2)$ daha fazladır (Demir, 2016). Dünya nüfusu son 100 yıl içinde (1950-2050) 4 kat artarken, yaşlı nüfusun 10 kat artacak olması önemli bir noktadır (Tekin \& Kara, 2016).

Dünya nüfusunun 2018 yılında \%9,1'ini yaşlı nüfus oluşturmuştur (Türkiye İstatistik Kurumu [TÜiK], 2019). DSÖ (2018) verisine göre, 2000 yılında 600 milyon olan 60 yaş ve üstü kişi sayısı, 2025'te 1,2 milyona, 2050'de ise 2 milyona çıkacaktır. Birleşmiş Milletler Ekonomik ve Sosyal İşler Departmanı (UN DESA) verisine göre, 60 yaş ve üstü 962 milyon kişi, küresel nüfusun yaklaşık \%13'ünü oluşturmuştur (UN, 2018; Usta \& Murat). 60 yaş ve üstü küresel nüfus, 1980'de 382 milyon, 2017'de iki kattan fazla artarak 962 milyona yükselmiştir. 2017'de her 8 kişiden biri 60 yaş ve üstüyken 2020'de her 5 kişiden birinin 60 yaş ve üstü olması beklenmektedir (UN, 2018).

Yaşlı nüfusun üçte ikisinden fazlası, gelişmekte olan ülkelerde yaşamaktadır ve bu sıklık gelişmiş ülkelerdekine oranla daha hızlı büyümektedir. 2050'ye gelindiğinde, dünyadaki yaklaşık her 10 yaşlıdan 8'inin gelişmekte olan ülkelerde yaşaması beklenmektedir. 2050'de yaşılıarın, Avrupa'daki nüfusun \%35'ini, Kuzey Amerika'daki nüfusun \%28'ini, Latin Amerika ve Karayipler'deki nüfusun \%25,ini, Asyardaki nüfusun \%24'ünü, Okyanusya`dakinin \%23'ünü ve Afrikardakinin \%9'unu oluşturacağı düşünülmektedir. Dünyada en fazla yaşı nüfusa sahip Japonya'da 90 yaş ve üzeri 2,06 milyon kişi yaşamaktadır. Dünya nüfusunda en hızlı yaşlanma hızı Japonya`da görülmektedir. Japonya`da 60 yaş ve üstü kişiler nüfusun \%33,4,ünü oluşturmaktadır. Japonya'yı \%29,4 ile İtalya, \%28 ile Almanya, \%27,9 ile Portekiz ve \%27,8 ile Finlandiya takip etmektedir (UN, 2018; The World Bank, 2018; Buz, Koçak \& Gözen 2018; Tekin \& Kara, 2016).

Ülkemizdeki yaşlı nüfus 2013 yılında 5 milyon 891 bin 694 kişi $(\% 7,7)$ iken, \%16 artarak 2018 yılında 7 milyon 186 bin 204 kişi $(\% 8,8)$ olmuştur. Nüfus projeksiyonlarına göre, yaşlı nüfus sıklığının 2023 yılında 8,6 milyona (\%10,2'ye), 2050 yılında 19,5 milyona (\%20,8'e), 2075 yılında ise 24,7 milyona (\%27,7'ye) çıkacağı tahmin edilmektedir. Yaşlı nüfus yaş grubuna göre incelendiğinde, 2013 yılında yaşlı nüfusun \%60,3'ü 65-74 yaş grubunda, $\% 32,2$ 'si $75-84$ yaş grubunda ve $\% 7,5$ 'i 85 ve daha yukarı yaş grubunda iken, 2017 yılında \%61,6'sı 65-74 yaş grubunda, \%29,7'si 75-84 yaş grubunda ve \%8,6'sı 85 ve daha yukarı yaş grubunda yer aldığı görülmektedir (TÜiK, 2019; T.C. Sağlık Bakanlığı, 2015).

Ortalama yaşam süresi son yüzyılda belirgin olarak artmış ve Japonya, Norveç, Kanada, Almanya gibi bazı ülkelerde 85'lere gelmiştir (T.C. Sağlık Bakanlığı, 2015). Bir birey 65 yaşına ulaştığında yaşaması beklenen ömür ortalama 17,7 yıl olmuştur. Ülkemizde doğuşta beklenen yaşam süresi 78 yıldır. Bu süre, erkeklerde 75,3 , kadınlarda 80,8 yıldır (TÜiK, 2019). 
Yalnız ya da eşiyle "bağımsız" yaşayan 60 yaş ve üstü kişilerin sıklığı, 143 ülke ve bölgeden edinilen veriye göre Afganistan'da \%2,3 iken, Hollanda'da \%93,4'tür. Hem Afrika'da hem de Avrupa'da, yaşlı kadınların yalnız yaşama sıklığı yaşlı erkeklerden iki kat daha fazladır. Afganistan, Tacikistan ve Pakistan'da, 60 yaş ve üstü kişilerin \%90'ından fazlası çocuklarıyla yaşamaktadır. Hollanda ve Almanya'da ise bu sıklık, \%10'dan daha azdır (UN, 2018).

Ülkemizde yaşlı bağımlılık hızı 2018 yılında \% 12,9 olmuştur. Nüfus projeksiyonlarına göre, yaşlı bağımlııı hızının 2023 yılında \%15,2, 2030 yılında \% 19,6, 2040 yılında \%25,3, 2060 yılında \%37,5 ve 2080 yılında \% 43,6 olacağı öngörülmektedir (TÜiK, 2019).

Yaşlanma ile birlikte insan vücudunda çeşitli değişiklikler meydana gelmekte ve bunun sonucu olarak da bazı sağlık sorunları ortaya çıkmaktadır. Bu konuda yapılmış olan çeşitli araştırmalar yaşılıarda en çok görülen sağlık sorunlarının hareket sistemi ile ilgili sorunlar, görme ve işitme problemleri gibi fizyolojik değişimlerin yol açtığı sorunlar ile hipertansiyon, kalp-damar sistemi hastalıkları, bazı kanserler, diyabet, kronik akciğer hastalıkları gibi daha ciddi hastalıklar olduğunu ortaya koymaktadır. Bu sağık sorunları bir yandan insan ömrünü ve yaşam kalitesini olumsuz olarak etkilemektedir (Bilir, 2004).

Nüfusun hızla yaşlanması, bazı bulaşıcı olmayan hastalıkların görülme riskini arttırmakta, bunun sonucu olarak da ulusal ve uluslararası halk sağlığı için yeni ve ciddi sorunlar ortaya çıkmaktadır (T.C. Sağlık Bakanlığı, 2015). Gelişmekte olan ülkelerde 2020 yılına kadar, tüm ölümlerin dörtte üçünün yaşlanma ile ilişkili olabileceği tahmin edilmektedir. Bu ölümlerin çoğunun kardiyovasküler hastalıklar, kanser ve diyabet gibi bulaşıcı olmayan hastalıklar sebebi ile meydana geleceği tahmin edilmektedir (Tekin \& Kara, 2016; DSÖ 2002, 2018).

Ülkemizde 65 yaş ve üzeri grubun \%90'ında 1, \%35'inde 2, \%23'ünde 3, \%15'inde 4 ve daha fazla kronik sağlık sorunu olduğu tahmin edilmektedir (T.C. Sağlık Bakanlığı, 2015). Ölüm nedeni istatistiklerine göre, 2017 yılında hayatını kaybeden yaşılıarın \% $45,1^{\prime} i$ dolaşım sistemi hastalıkları, \%16,2'si iyi ve kötü huylu tümörler, \%14,2'si solunum sistemi hastalıkları nedeni ile hayatını kaybetmiştir. Alzheimer hastalığından ölen yaşlıların sıklığı 2013 yılında \%3,6 iken, bu sıklık 2017 yılında \%4,6 yya yükselmiştir (TÜiK, 2019).

Yaşlanmanın bireye ve topluma getireceği yükün hafifletilebilmesi için aktif, sağlıklı, üretken, başarılı birey ve topluma ulaşmak hedefi, 1960'lı yıllardan itibaren öne sürülmüştür. DSÖ tarafından 1990'lı yıllarda dünyanın gündemine getirilmiş bir kavram olan aktif yaşlanma; "kişiler yaşlandıkça yaşam kalitelerinin zenginleşmesi için sağlık, topluma katıım ve güvenlik fırsatlarının en iyi düzeyde sağlanması süreci" olarak tanımlamakta ve tüm bireylere bu fırsatların sağlanmasını savunulmaktadır. Bir başka deyişle aktif yaşlanma; sağlıklı olma halinin korunmasıyla birlikte yeterli beslenme, fiziksel ve zihinsel olarak aktif olma, güvenli bir çevrede yaşama, çalışma ve sosyal çevre içinde yer alma koşullarını yerine getirebilen bireylerin yaş alma süreçlerine verilen isimdir (T.C. Avrupa Birliği Bakanlığı, 2011).

"Aktif Yaşlanma" programı içinde öncelenen konular; yaşamın ileri dönemlerinde de beklenmeyen ve erken ölümlerin önlenmesi, bulaşıcı olmayan hastalıkları olan bireylerin 
hastalıklarına bağlı engellilik durumu yaşamamaları, bireylerin ileri yaşlarında da yaşamdan zevk alabilmeleri, yaşı bireylerin toplumun sosyal, politik, ekonomik aktivitelerine katılabilmeleri, sağlık harcamalarının daha az maliyetli olması ve bu giderler için devletin sorumluluğunun sağlanmasıdır (Framework, 2004). Birleşmiş Milletler tarafından 2002 yılında yapılan Dünya Yaşlanma Toplantısı'nda (United Nations World Assembly on Ageing) "aktif yaşlanma", zinde yaşılıların yanı sıra kırılgan yaşlıyı da göz önünde bulunduran ve bir gereksinimden çok bir hak olarak vurgulanmıştır (Framework, 2004; Liu et al., 2018; Demir, 2018).

Yaşlı ve yaşlılığa karşı inançlar ve tutumlar kültürden kültüre değişmektedir. Bazı toplumlar, yaşlılığa daha çok olumsuz nitelikler atfederken (işe yaramaz, değersiz, güçsüz, yetersiz gibi) Japonya gibi geleneksel toplumlarda ise, yaşlılara hürmet edilerek, bilgi birikimleri ve deneyimlerinden yararlanılmakta ve yaşlının sosyal statüsünün daha yüksek olduğu gözlenmektedir (Akdemir, Çınar \& Görgülü, 2007; Çilingiroğlu \& Yaşlılık, 2004). Türk kültüründe, yaşlıya saygı, yaşlının sözüne itibar etme ve yaşlısına sahip çıkma geleneksel ve değişmez bir beklenti iken yaşlının toplum içindeki statüsü ve saygınlığı günümüzde değişmektedir. Kentleşme, göçler ve sanayileşmenin artması, ekonomik zorluklar, kadının çalışma hayatına girmesi, sosyal yaşamın değişmesi, ataerkil aile yapısından çekirdek aile yapısına geçiş özellikle büyük şehirlerde aile yapılarında önemli değişikliklere neden olmaktadır (Öztek \& Kubilay, 2008). Ülkemizde yaşanan bu hızlı ve çok yönlü değişimler sosyal yaşantıda ve iş yaşantısında daha çok dinamik olan kişilerin ve gençlerin tercih edilmesine yol açmakta, yaşlıların ikinci plana itilmesine ve kültürel değerlerimizde bazı değişimlere neden olmaktadır (Akdemir et al., 2007; Çilingiroğlu \& Yaşılıık, 2004).

Günümüzde yaşlılık ile ilgili politikalar ve programlar yaşam kalitesini artırmaya ve sağlık durumunu daha iyi hale getirmeye odaklanmaktadır. DSÖ tarafından "Yaşlılara yapılan sağlık harcamalarını azaltmak yerine öncelikli hedef olarak yaşılıarın toplumun üretken ve aktif bireyleri olarak yaşayabilmeleri için eyleme geçmek" önerilmiştir. DSÖ’nün "Yaşama yıllar ekledik, şimdi yıllara yaşam eklemeliyiz" deyimi ile üretken, başarılı ve bağımsız bir yaşlanma hedeflenmektedir. Yaşlı bireylerin yalnızca fiziksel olarak aktif olmalarını değil, aynı zamanda işgücüne dahil olmaları ve sosyal, ekonomik, kültürel, ruhsal ve medeni hayata katılmaları üzerine vurgu yapılmaktadır. Tüm bunlar dikkate alındığında, aktif yaşlanma kavramının yanı sıra "başarılı yaşlanma", "sağlıklı yaşlanma”, "üretken yaşlanma" kavramları da kullanılmakta, kimi zaman literatürde bu kavramların birbirinin yerine de kullanıldığı görülmektedir. Sağlık koşullarından ötürü fiziksel olarak yeterince aktif olamayan bir grup yaşlıyı dışladığı gerekçesi ile "aktivite teorisi”, çalışmakta olmayan bir grup yaşlıyı dışladığı gerekçesi ile "üretken yaşlanma", bireylere gerçekçi olmayan beklentiler yüklediği ve kişileri tek tipleştirdiği yönünde eleştirilen "başarılı yaşlanma" kavramı da tartışılmaktadır (Framework, 2004).

Başarılı yaşlanma; yalnızca sağlık yönünden değil aynı zamanda psikolojik ve sosyal yönden de tam bir iyilik halini işaret eden bir kavramdır. Yaşam uzunluğu, biyolojik ve zihinsel sağlık, bilişsel yeterlilik, sosyal yeterlilik ve üretkenlik, kişisel kontrol ve yaşamdan zevk alma başarılı yaşlanmanın en temel göstergeleridir (DPT, 2007; Kılıç D., 2009). 
Araştırmalarda, "aktif yaşlanmanın belirleyicileri; kültür, cinsiyet, ekonomik faktörler, sağlık ve sosyal hizmetler, sosyal-çevresel belirleyiciler, fiziksel-çevresel belirleyiciler, kişisel faktörler ve davranışsal faktörler olarak saptanmıştır (Framework, 2000; Tutal, 2016).

Sağlık ve işlevselliğin sürdürülmesi için etkinlikler, boş zaman aktiviteleri, kulüp ve sosyal ortamlara katıım, çevre ile temasın sürdürülmesi, fiziksel aktivite, bulmaca benzeri yöntemler ile zihin egzersizleri, günlük işlerin yapılması, herhangi bir hobisinin olması önemlidir (Tereci, Turan, Kasa, Öncel, \& Arslansoyu, 2016). Bu etkinliklerin yapılması yaşıının kendi sağlığı ile ilgili endişe duymaması, depresyonda olmaması, yeti yitiminin olmaması ve algılanan sosyal destek ile yaşam doyumunu ve dolayısıyla yaşam kalitesini artırmaktadır.

Türkiye de dünyadaki yaşlanmaya benzer süreçlerden geçecek ve toplum yaşlanmasının getirdiği sorunlarla yüzleşecektir (Tekin \& Fatih, 2016). Bu sorunlarla mücadelede sağlık politikaları, yaşlıların bağımsız biçimde yaşamalarına ve topluma entegre olmalarına öncelik vermektedir (WHO, 2008.) Doğum öncesinden başlayarak sağlıklı beslenme, düzenli egzersiz, sağlıklı yaşam alanlarının sağlanması gibi bütüncül ve multisektöriyel bir yaklaşım benimsenmelidir. Politikacılar, sivil toplum örgütleri ve sağlık çalışanları başta olmak üzere, tüm topluma yaşlıık ile ilgili bilinçlendirme çalışmaları yapılmalıdır.

Birey, toplum ve sağlık sistemleri tarafından yaşam boyu sağlığın geliştirilmesi ve aktif yaşlanmanın öncelenmesi ile sağlıklı ve aktif yaş alabilen toplumlar oluşacaktır. Bu doğrultuda yol alan toplumlar dünya ülkeleri arasında da rekabet konusunda avantajı olacaktır.

\section{Kaynakça}

- Akdemir, N., Çınar, F. İ., \& Görgülü, Ü. (2007). Yaşılığın algılanması ve yaşı̆ı ayrımcılığı. Turkish Journal of Geriatrics, 10(4), 215-222.

- Aslan, D. Aktif yaşlanma kavramı, Hacettepe Üniversitesi Tıp Fakültesi Halk Sağlığı ABD, Erişim Adresi: http://www.turkgeriatri.org/halksagligi?id=12

- Bakanlığı, T.C. Avrupa Birliği (2011). 2012 Avrupa aktif yaşlanma ve nesiller arası dayanışma yılı hakkında bilgi notu Erişim Adresi: https://www.ab.gov.tr/files/SBYPB/Sosyal\%20Politika\%20ve\%20 \%C4\%B0stihdam/aktif_yaslanma_bilgi_notu.pdf).

- Bakanlı̆ı, T.C. Sağlık (2015). Türkiye sağlıklı yaşlanma eylem planı ve uygulama programı 2015-2020. Türkiye Halk Sağlığı Kurumu Kronik Hastalıklar, Yaşlı Sağıı̆ı ve Özürlüler Daire Başkanlığı, Yayın (960), 22-30.

- Bilir, N. (2004). Yaşlanan toplum, Hacettepe Üniversitesi Tıp Fakültesi Halk Sağlığı ABD, 1. Erişim Adresi: http://www.geriatri.org.tr/pdfler/YaslananToplum.pdf

- Buz, S., Koçak Ertan, Y. \& Gözen, Ö. (2018). Türkiye'de yaşlllara sunulan hizmetlerin birleşmiş milletler yaşlılık ilkeleri çerçevesinde değerlendirilmesi: Ankara örneği Akademik Sosyal Araştırmalar Dergisi, Yı: 6, Sayı: 77, S. $388-410$ 
- Cankurtaran, M. (2005). Yaşlılık, yaşlanma mekanizmaları, antiaging ve yaşam tarzı değişiklikleri. 7. Ulusal iç Hastalıkları Kongresi. Antalya. Erişim Adresi: http://www.tihud.org.tr/uploads/content/kongre/7/7.15. pdf

- Çolak, M., \& Özer, Y. E. (2015). Sosyal politika anlamında aktif yaşlanma politikalarının ulusal ve yerel düzeydeki analizi. Elektronik Sosyal Bilimler Dergisi, 14(55), 115-124. http://dergipark.gov.tr/download/ article-file/70669

- Çilingiroğlu, N., \& Yaşlılık, D. S. (2004). Yaşı ayrımcılığı. Türk Geriatri Dergisi, 7(4), 225-230.

- Demir, O. (2016). Nüfus politikaları ve Çin, Fransa ve Türkiye örneklerinin değerlendirilmesi. Social Sciences, 11(1), 41-61.

- Demir, Ş. (2018). İkinci dünya yaşlııık toplantısı' nın (Madrid Planı) ülkelerin yaşlıık politikası. 30, 365-380

- DPT (2007). Türkiye'de yaşılıarın durumu ve yaşlanma ulusal eylem planı 2007. http://ekutup.dpt.gov.tr/ nufus/yaslilik/eylempla.pdf (Erişim Tarihi:18 Şubat 2019)

- Kılıç D. Yaşı sağlığı. In: Erci B (ed). Halk Sağlığı Hemşireliği. Ankara: Fırat Matbaacılık, 2009: 133-155.

- Kunkel, S. R., \& Morgan, L. A. (2015). Aging, society, and the life course: Springer Publishing Company.

- Kurumu, T. D. (2017). Türk Dil Kurumu Güncel Türkçe Sözlük.

- Liu, L.-K., Chen, C.-H., Lee, W.-J., Wu, Y.-H., Hwang, A.-C., Lin, M.-H., . . . Arai, H. (2018). Cognitive frailty and its association with all-cause mortality among community-dwelling older adults in Taiwan: Results from I-lan longitudinal aging study. Rejuvenation research, 21(6), 510-517.

- Morgan, L. A., \& Kunkel, S. R. (2007). Aging, society, and the life course: Springer Publishing Company.

- Organization, W. H. (2004). Active ageing: a policy framework. Geneva: WHO; 2002. http://whqlibdoc. who. int/hq/2002/who_nmh_nph_02, 8.

- Organization, W. H. (2003). The world health report 2003: shaping the future: World Health Organization.

- Öztek, Z., \& Kubilay, G. (2008). Toplum sağlığı hemşireliği: Palme Yayıncılık.

- Sonbahar, A. Başarılı yaşlanma algısı: farklı yaş gruplarından bireylerin yaşlıı̆a bakışı.

- Soyuer, F., \& Soyuer, A. (2008). Yaşılıık ve fiziksel aktivite. Turgut Özal Tıp Merkezi Dergisi, 15(3), $219-224$.

- TEKIN, Ç. S., \& Fatih, K. (2016). Dünyada ve Türkiye'de yaşlılık. Uluslararası Bilimsel Araştırmalar Dergisi (IBAD), 3(1), 219-229.

- Tereci, D., Turan, G., Kasa, N., Öncel, T., \& Arslansoyu, N. Yaşlılık kavramına bir bakış. Ufkun Ötesi Bilim Dergisi, 2016(1), 84-116.

- Teşkilatı, D. P. (2007). Türkiye'de yaşlıların durumu ve yaşlanma ulusal eylem planı. Sosyal Sektörler ve Koordinasyon Genel Müdürlüğü, Yayın No DPT, 2741.

- Tutal, O. (2016). Yaşlılık, yaşam çevresi ve evrensel tasarım. Yaşlıık Disiplinlerarası Yaklaşım, Sorunlar, Çözümler (Edit: Velittin Kalınkara) Ankara, Nobel Akademik Yayıncılık Eğitim Danışmanlık Tic. Ltd. Şti, 489-507.

- TUIK,18 Mart 2019 Haber Bülteni Sayı: 30699 İstatistiklerle Yaşlılar, 2018 www.tuik.gov.tr

- United Nations (UN) (2018). World population ageing 2018. Department of Economic and Social Affairs Population Division, New York https://www.un.org/development/desa/publications/2018-revision-ofworld-urbanization-prospects.html

- Usta, G., \& Murat, G. İşgücü piyasasında yaşlılar ve aktif yaşlanma: avrupa birliği ve Türkiye değerlendirmesi.

- WHO global report on falls prevention in older age, World Health Organization. Ageing-2008- bo ok s . google.com https://www.who.int/en/news-room/fact-sheets/detail/ageing-and-health

- Active Ageing: Towards Age-Friendly Primary Health Care. Towards Age-Friendly Primary Health Care, WHO. http://whqlibdoc.who.int/hq/2004/WHO_CHP_HPR_04.02.pdf. ISBN 9241592184 World Health Organization 2004

- World Health Organization Noncommunicable Diseases and Mental Health Cluster Noncommunicable Disease Prevention and Health Promotion Department Ageing and Life Course active ageıng: a polıcy framework https://extranet.who.int/agefriendlyworld/wp-content/uploads/2014/06/ WHO-Active- Ageing-Framework.pdf 